\title{
DEPOIMENTO
}

\section{Programa Habitacional, Infraestrutura e Desordem Urbanística}

Álvaro Pessôa ${ }^{1}$

1. Agradeço a gentileza do convite para repensar ideias sobre o assunto urbanismo, habitação, autoconstrução e infraestrutura urbanística das cidades brasileiras nos últimos 140 anos. Afinal tive a oportunidade, em 1970, aos 30 anos, de estudar os temas, quando partilhei ensinamentos com tantos, aprendi e ensinei e, afinal, advoguei para entidades públicas atuando em habitação e infraestrutura por muitos anos.

2. Um sábio conselho para velhos é que falem pouco, pois repetem a mesma história muitas vezes. Vou procurar contar uma história de maneira despretensiosa, sem requintes e rebuscados.

3. Esclareço ainda que a maioria das inovações urbanísticas que se aplicaram ao Brasil, pelo menos até 1960 e das quais adiante se dão notícia, ocorreram nesta "muy leal e heroica cidade do Rio de Janeiro". Desde a criação do Município neutro, no Império, em 1835, em território do atual Município do Rio de Janeiro ocorreu quase tudo. Ele já foi município neutro, depois Distrito Federal (a partir da República Federativa) e, após, Estado da Guanabara, até a transferência da capital para Brasília em 1960.

4. A partir de 1975, com a fusão dos dois estados, volta a ser Município do Estado do Rio de Janeiro. No território acima descrito vivia e pulsava uma economia pujante, com cintilações de muitas inteligências privilegiadas, fortíssima influência do urbanismo francês, educação de primeira, economia cafeeira do Vale do Paraíba que assegurava muita riqueza. Para completar o colar de vantagens, esse espaço geográfico tinha como locatário o melhor inquilino do mundo: a União Federal, com Senado Federal e a Câmara, além do Supremo Tribunal Federal, todas as organizações militares, fortíssima indústria naval e um parque industrial de tecidos dos quais se veem as marcas até hoje ${ }^{2}$.

5. Operários moravam no local de trabalho e tinham o aluguel deduzido do salário, mas não gastavam com transporte, morando no trabalho com dignidade. As favelas ainda não eram expressivas, sendo muito mais

1 O jurista Álvaro Pessoa nasceu em 1940, graduou-se pela Faculdade de Direito da Universidade do Brasil (UFRJ, 1963) e cursou mestrado em Direito na Yale Law School, concluído em 1970. Atuou profissionalmente como professor da PUC-RJ e da UFRJ, Advogado concursado do BNH (Banco Nacional de Habitação) e agente público junto à FUNDREM (Fundação para o Desenvolvimento da Região Metropolitana do Rio de Janeiro), porém sua atuação mais importante foi como chefe da Consultoria Jurídica do IBAM (Instituto Brasileiro de Administração Municipal), responsável pelo assessoramento a inúmeras prefeituras, no desenvolvimento de experiências pioneiras de aplicação de instrumentos jurídicos de controle e socialização da propriedade do solo urbano. É autor das obras "Direito do Urbanismo: uma Visão Sócio-Jurídica" e "O Uso do Solo em Conflito", ambas do início dos anos 1980, e consideradas pioneiras na literatura especializada em Direito Urbanístico no Brasil.

2 As grandes fábricas de tecido tinham suas vilas operárias, como ainda se pode ver, subindo a rua Lopes Quintas, a fábrica Bangu no subúrbio do mesmo nome, a fábrica de tecidos da Rua Maxwell em Vila Isabel. 
comum a vida em cortiços no bairro de Botafogo, entre os quais o "cabeça de porco"'s.

6. O direito positivo era moderno e os magistrados sábios, a ponto de se poder usar, em 1920, para alargar a Avenida Rio Branco, a DESAPROPRIAÇÃO POR ZONA, instrumento moderníssimo que o Barão de Haussman tinha utilizado em Paris, para estabelecer o conjunto de boulevares que partem todos do Arco do Triunfo. Tivemos também a CONTRIBUIÇÃO DE MELHORIA, depois consagrada por legislação federal, Decreto Lei 195 de 1967, que cria um imposto ou taxa (contribuição incidindo sobre a mais valia imobiliária).

7. Getúlio Vargas era um gerente de alto nível. Não tinha o menor receio de cercarse de um Ministério altamente competente e, dessa época, se projeta, a partir do Rio de Janeiro, moderna legislação de proteção ao Patrimônio Histórico (Decreto Lei 25 de 1937), a Lei de Desapropriação (Lei 3365 de 1941), loteamentos urbanos (Dec. lei 58, de 1937), legislação de proteção ao Fundo de Comércio (Decreto 24.150 de 1934), leis que tratam dos Imóveis do Patrimônio da União (Decreto Lei no 9760 de 1946). Planos de ocupação urbana da cidade como o Plano Agache, depois abandonado ${ }^{4}$.

8. A partir de 1950 e, sobretudo a partir de 1960 (mudança da capital) a cidade perdeu seu dinamismo, e, mais grave ainda, perdeu seu sistema educacional implantado por Anísio Teixeira, cujo epicentro era o Instituto de Educação, onde se treinavam professoras altamente categorizadas que recebiam salário desde o primeiro dia de aula como alunos. Foi a matriz dos CIEPS que Darcy Ribeiro criaria depois.

9. Gostaria de começar com uma declaração de princípios não ideológica, feita por um estadista pernambucano que se chamou Agamenon Magalhães (notabilizouse por várias razões, mas foi pioneiro em criar o SERVIÇO NACIONAL PARA ERRADICAÇÃO DO MOCAMBO na década de 30). Agamenon formulou um princípio de genial prudência em relação à justa distribuição da produção e do consumo: "todos os negócios em que o LUCRO e o PREJUízo sejam certos, DEVEM PERTENCER À ADMINISTRAÇÃO PÚBLICA”. Pode haver até concessão ou delegação, mas originalmente são públicos.

10. Se essas ideias puderem ser uteis às futuras gerações já estarei plenamente recompensado. Só exteriorizo as lembranças por uma razão prosaica (80 anos depois, sobra pouca gente viva para contar como aconteceu) e outra mais elevada: admiração pelos batalhadores da luta pelo teto, tanto dos menos (como dos mais) necessitados, pelo Brasil a fora. Trabalham ensinando, planejando, construindo, tentando melhorar a vida e lutando contra os maiores inimigos dos países subdesenvolvidos: a mesquinharia, a mediocridade, a fofoca, a igrejinha, a panelinha, a inveja, o nepotismo, a falta de estudos. Esses maus hálitos da alma que constituem a coluna vertebral do SUBDESENVOLVIMENTO.

11. Quem desejar ler um estudo mais profundo, desses temas, deve procurar o livro "Sistema Financeiro da Habitação", de José Maria Aragão. Cada um dos projetos do $\mathrm{BNH}$ teve sua raiz no passado, como devem ser as coisas com pé e cabeça. Exemplo perfeito de projeto sem pé nem cabeça, é o tal do DIREITO DA LAGE, que um ministro mais precipitado que inovador teve a coragem de endossar e

3 Retratado no livro O CORTIÇO, de Aloísio de Azevedo.

4 Todos os Planos Urbanísticos do Rio de Janeiro podem ser estudados no livro da Prof. ${ }^{\text {a }}$ Verena Andreatta, publicado em 2006, com título “Cidades Quadradas, Paraísos Circulares.”

5 Sistema Financeiro da Habitação - Ed. Juruá, 1999 - José Maria Aragão. 
defender. O SFH incorporou ideias centenárias do urbanismo e da habitação no Brasil pelos últimos cem anos, daí ter vivido 30 anos. Nenhum organismo brasileiro de financiamento habitacional sobreviveu até nossos dias! Foram todos extintos!

12. A grande inovação trazida pelos tempos mais recentes com o $\mathrm{BNH}$, ocorreu no subsolo das cidades: a infraestrutura urbana. Aquele segmento da economia que atua poderosamente sobre o preço da habitação e cujo custo (E QUEM O PAGA) OS PODEROSOS JAMAIS QUEREM DEFINIR a quem cabe. A Espanha resolveu o problema na Constituição ditando: "pertencem à comunidade as mais valias decorrentes do investimento público em infraestrutura". Ao tentar embutir ideia semelhante na Comissão de Notáveis da Constituinte de 1988, esse modesto escriba ouviu de um "notável" (tributarista famoso) que "mais valia é coisa de comunista". Não deve ser tão comunista assim, pois é como se chama o LUCRO IMOBILIÁRIO lusitano, mas a ignorância sempre foi grande e o preconceito pior.

13. Quase tudo começa no Rio de Janeiro, quando o Imperador D. Pedro II, verificou, em meados de 1880, que os morros da cidade começavam a ser desordenadamente ocupados pela população carente e mandou tomar providências a respeito. O maior receio dos habitantes do asfalto, em épocas de ausência de antibióticos e remédios poderosos, era a falta de higiene entre os favelados. Após informar-se sobre o assunto, o Visconde de Paranaguá desenvolveu o que seria, ainda hoje, considerado um modelo econômico realista para equacionar o problema. Pelo Decreto-legislativo $\mathrm{n}^{0} 3.151$, de nove de dezembro de 1882, o Imperador concedeu ao empresário Américo Castro licença para implantar infraestrutura urbana e construir habitações para aluguel com preço tabelado. Inúmeras concessões desta ordem foram efetivadas no Império e nos primórdios da República.

14. Recebendo poderes para desapropriar, urbanizar e construir, bem como isenções de impostos diversos por vinte anos, os empresários constituíram companhias e iniciavam a atividade econômica sabendo que o produto final (habitação) seria alugado (a preço tabelado) e não vendido. A dimensão do imóvel era definida pelo número de habitantes (como hoje na Suíça) e não pelo número de quartos e acomodações.

15. Para os usuários de tais habitações não havia o "sonho da casa própria", mas também não havia o "pesadelo da prestação". A bandeira da casa própria popular só vai surgir décadas após. Aparece como ideário de partidos políticos já no ocaso da República Velha, habilmente empunhado por Getúlio Vargas. O Diário da Noite de 24.12.1933 estampava em manchete: "Será uma realidade breve, a casa própria do trabalhador nacional".

16. Este embrião de política habitacional desenvolvido no Império, teve sucesso para o nível de dificuldade de problema de então e as condições econômicas da época, por duas razões: em primeiro lugar previu solução urbanística e habitacional concomitantes, mas tudo à custa dos cofres empresariais. Hoje, ao contrário, com a estatização reinante, os cofres públicos assumem os custos da infraestrutura urbana, e uma privilegiada minoria do público em geral (bem como o empresariado) faz a colheita das edificações e dos apartamentos, sem pagar qualquer tributo direto pelo benefício recebido sob a forma de infraestrutura e equipamento urbano.

17. "Plantar" e "colher" apartamentos num edifício é igualzinho à plantação e colheita de milho, soja ou cana. A operação capitalista é a mesma, com a enorme diferença de que os insumos (na terra urbana) são pagos 
pela comunidade. Aliás, o terreno em construção chama-se, muito apropriadamente, CANTEIRO DE OBRAS. Desse canteiro adubado com dinheiro público, sai a safra ou a colheita de apartamentos. A solução dos tempos do Império também era adequada, pela compatibilidade entre o preço do aluguel e o valor real do salário. Finalmente, o empresário ainda não era (como hoje) uma ilha cercada de governo por todos os lados, nas exatas palavras de Hélio Beltrão.

18. O modelo habitacional acima descrito, ainda que não consagrado como política oficial de governo, sobreviveu à proclamação da República e chegou até o mandato do Mal. Hermes da Fonseca. Só então a partir da década de 1910, quando se promoveu a implantação do bairro Marechal Hermes no Rio de Janeiro, a administração pública passou a financiar (e não mais a compensar com isenções plurianuais de tributos) construções de casas populares. Foi nosso maior equívoco! Dessa época data também a criação da Caixa Econômica Federal, com o expressivo nome de Casa do Monte do Socorro, que começou emprestando aos mais pobres mediante penhor de jóias.

19. A partir de 1930, sobretudo em decorrência da profunda transformação que o Governo Vargas iria imprimir à economia, ocorre uma nova alternativa de financiamento. Paralelamente aos recursos alocados pela Caixa Econômica Federal, as Carteiras de Habitação dos Institutos de Previdência ${ }^{6}$ passam também a servir de fonte de financiamento ao empresariado, para construção de casas populares, ou à classe média para aquisição de casa própria.

20. Por outro lado, na mesma época, sobretudo no Rio de Janeiro, por intermédio da Light \& Power, que monopolizava a implantação de infraestrutura, como concessionária de luz, água, gás e transporte na cidade, foram lançados os loteamentos de Botafogo, Copacabana, Jardim Botânico, Ipanema e Leblon, fornecendo lotes equipados e acessíveis ao mercado.

21. Contribui ainda para a oferta de habitação, uma tendência nacional do imigrante português: destinar seu capital para a construção de casas de vila, depois alugadas aos menos favorecidos. Tal tendência foi cortada pela raiz, quando a demagogia CONGELA o preço dos alugueres ${ }^{7}$ e torna o investimento desinteressante.

22. Também em São Paulo, a partir de 1920, a Cia. City of São Paulo Improvements and Freehold Land, passa a oferecer ao mercado lotes de terrenos urbanisticamente equipados com água, luz, gás, transporte e telefone. Os custos da infraestrutura urbana de tais áreas loteadas eram suportados pela própria iniciativa privada, não havendo sangria dos cofres públicos. O modelo de construção da casa própria articulado com o desenvolvimento urbano, ainda aí, era viável e, em São Paulo, seguiu o modelo urbanístico inglês ${ }^{8}$.

23. A reconstitucionalização do País em 1946 abre efetivamente novos horizontes ao seu destino, mas paulatinamente começam a crescer dois males (que haviam germinado nas décadas anteriores), fatais para os futuros programas habitacionais brasileiros.

6 Antes da unificação da Previdência, cada categoria tinha seu Instituto de Previdência, alguns deles modelares, como o IAPI, o IAPB, o IAPC e o IAPETEC. Em 1966 foram todos unificados.

7 A lei 1300 de 1950 fica em vigor de 1950 até 1965, quando foi expressamente revogada, mas aí já era tarde.

8 São os lindos projetos denominados “jardins” da cidade: Butantã, Vila Inah etc... 
24. O primeiro mal consistiu em acreditar-se que um programa habitacional financiado com recursos públicos poderia esgotar-se em si próprio, sem a devida alteração de natureza fundiária. A falta de política fundiária, conjugada com recursos incentivados e alocados ao programa habitacional, contribuiu sempre (e mais do que nenhum outro fator) para os altos níveis de custo das unidades habitacionais por ele produzidas. Sem falar na ausência de preocupação com a infraestrutura urbana

25. O colapso das Carteiras Habitacionais dos Institutos de Previdência e da Fundação da Casa Popular deveu-se, sobretudo à inflação elevada conjugada com a falta de correção monetária das prestações, mas o sistema fracassaria de qualquer forma (mesmo se o preço fosse corrigido monetariamente), como o futuro se encarregou de demonstrar.

26. O segundo mal que bateu rijo nos programas habitacionais brasileiros dos últimos trinta anos foi, paradoxalmente, o excesso de estatização. Aquilo que inicialmente era apenas um espinho fincado no calcanhar, veio a degenerar em abcesso que gangrenou todo o organismo. Explico melhor. Com o modelo imperial de 1880, e todos os outros acima descritos, o segmento empresarial arcava com as responsabilidades de implantar infraestrutura urbana e construir para alugar a preço tabelado, mas se beneficiava das isenções plurianuais de diversas taxas e impostos. Tal técnica é, ainda hoje, muito utilizada no programa habitacional espanhol e no italiano. Desse modo, a intervenção estatal no processo produtivo é quase nula.

27. A partir da República, a administração também não praticou intervenção excessiva, na medida em que concedia às empresas concessionárias privadas multinacionais, os serviços públicos essenciais à urbanização. A Light, a Society Annonime du Gás e as concessionárias de transportes públicos, fizeram seu trabalho. Estas é que promoviam o crescimento das cidades, pela circunstância de serem, elas próprias, indutoras do processo de desenvolvimento urbano, ao promoverem melhoramentos. O modelo, como vimos, também aí continuava economicamente justo.

28. Ocorre que, a partir dos anos cinquenta, com a Fundação da Casa Popular, passa a ser promovido o modelo virtualmente suicida. A administração pública inicia um processo de inchamento burocrático, começa a desempenhar atividades até então tipicamente da iniciativa privada (nos três níveis de Governo) e empreita patrocinar os custos de implantação da infraestrutura e equipamento. Continua, porém, sem definição, a política fundiária. Também não se tributam diretamente os benefícios oferecidos aos particulares (sob a forma de água, telefone, luz, esgoto, transporte e arruamento), de forma a assegurar o acesso de todos às vantagens da urbanização.

29. É a mais perversa e injusta forma possível de distribuir a renda pública, tirando de quem não era proprietário e beneficiando ainda mais quem já era. Esta iniquidade continua a ser perpetrada ainda hoje! Não se fala mais em desapropriação por zonas previstas na Lei de Desapropriação 3.365, de 21/06/1941, e na Lei 125, de 1967 (contribuição de melhoria).

30. A política habitacional definida pela Lei 4.380 , de $1964^{9}$, persistiu no mesmo erro histórico e não se pense que a maior parcela de culpa coube ao BNH. O sistema habitacional foi concebido (vertente inicial clara), para tornar-se apenas uma

9 Lei que criou o BNH e instituiu a correção monetária nos financiamentos públicos de habitação. 
agência de financiamento habitacional e implantação de infraestrutura, fornecendo emprego às classes menos favorecidas.

31. A solução para as distorções acima apontadas não está, nem nunca esteve ao alcance da mão da empresa pública. A solução está (como sempre esteve), nas mãos dos formuladores de modelo econômico e, dentro deste, avulta a necessidade de definirse qual é o modelo de produção capitalista da cidade no Brasil.

32. No passado recente, enfrentamos várias incompatibilidades do modelo. A primeira incompatibilidade resultava da função efetiva para a qual se queria o $\mathrm{BNH}$, dentro do modelo modernizador Roberto Campos, calcado em economia dualista. Pretendia-se, fundamentalmente, que o Banco funcionasse como órgão de estímulo à indústria de construção civil, natural empregadora da mão-de-obra numerosa e desqualificada. Esta, ficando ociosa em decorrência da reorientação da economia que se ia proceder, constituía perigosa ameaça para a funcionalidade do modelo. Casa popular mais (ou menos) barata era consequência e não meta principal.

33. A segunda incompatibilidade decorria dos objetivos legais - onde adquirira prioridade a erradicação de habitações onde fosse subumana a condição de vida - embora a lei não esclarecesse quem ou como se pagava a conta da casa nova ou o aumento de renda correspondente. Talvez presumisse que ele ia ocorrer num passe de mágica dos contos de fada ou que se morasse em favelas por diletantismo. Só mais tarde o $\mathrm{BNH}$ passaria a preocupar-se com financiamento de habitação de classe média.

34. A ideia de erradicar favelas não surgira por acaso. Fora importada. Na primeira metade dos anos 60 estivera em grande moda nos Estados Unidos. O fundamento (bastante discutível) de tal modismo era o de que as favelas impunham altos custos sociais aos moradores de cidades. Acontece que naquele país as pesquisas e os instrumentos político-institucionais funcionam. Tão logo os juízes norte americanos se aperceberam do absurdo de tal concepção proibiram remoção de favelas. Ficou sepultada uma era da política habitacional americana conhecida como "The Federal Buldozer Policy".

35. Infelizmente nossa sociedade não importou junto com a ideia as instituições políticas. Quando afinal aprendemos, ou pelo menos quase, que não se removem indiscriminadamente favelas e muito menos pelos métodos iniciais, graças aos trabalhos científicos de Gilda Blank, Carlos Nelson Ferreira dos Santos, Olga Bronstein, Licia Valadares e Janice Pearlman ${ }^{10}$, muitas comunidades e famílias destroçadas já haviam pago altíssimos preços. Em Vila Kennedy, por exemplo, dois anos após as remoções, mais de 50\% das famílias haviam sido abandonadas pelo marido, elevando a níveis altíssimos a incidência de prostituição.

36. Os defensores da utopia idealista da casa própria popular para todos os brasileiros, ao formularem seus projetos de gabinete, nunca devem esquecer duas coisas: Vila Kennedy entre outros amargos (para os removidos) exemplos e de que o denominador comum da casa popular no Brasil chama-se pobreza. Também não devem esquecer duas contas elementares para saber quão profunda é a pobreza. A primeira é que, na Região Metropolitana do Rio de Janeiro, o custo médio de produção capitalista da mais barata habitação popular (apenas $40 \mathrm{~m}^{2}$ ) é muito alto. A segunda conta é que pelos dados fornecidos pelo insuspeito e reputado IPEA, na mesma Região Metropolitana, 30\% da população economicamente ativa recebe menos de um salário mínimo, isto é, está fora de qualquer programa habitacional em vigor. 
37. Ora, se algum dia o Governo federal estiver realmente interessado, em programas de desenvolvimento urbano e habitacionais, deve ser lembrado que casa própria para estes 70 milhões de pessoas será incessível durante muito tempo.

38. Há, porém, já em funcionamento, admiráveis e genuínas alternativas caboclas para o problema de moradia. Foi o que se verificou, por exemplo, no Município de Camaçari, na Bahia, onde o migrante sertanejo foi apresentado à vida urbana, através da aquisição de um lote mínimo $(80 \mathrm{~m} 2)$, cuja propriedade vai pagar modicamente ao Município. $O$ equipamento urbano do lote é apenas um ponto de água para cada vinte lotes: pequenas construções para comércio vicinal e venda de artesanato. Além de uma ciclovia para ida e volta do trabalho em bicicleta e sem engarrafamentos. A casa é autoconstruída ou construída em mutirão, sob orientação municipal, que vende a preço de custo material comprado em demolição. O posto de trabalho é perto da habitação como é óbvio!

39. A melhora de salário leva a um segundo patamar da vida urbana, onde então cada lote tem água, rede de esgoto ou fossa séptica. Mais nada. O conjunto ainda não é agradável à vista e a moradia e autoconstruída. O terceiro estágio é que se consolida através de aquisição da casa.

40. Bem mais eficaz do que criar o Ministério das Cidades, ter-se editado o Estatuto das Cidades e o Estatuto das Metrópoles. Onde devia ter ocorrido alteração, não houve.

41. Pode ser desagradável que um prefeito ou governador seja convidado a inaugurar torneiras e banheiros em época de fausto, máscara e ostentação. É assim, porém, que a saúde pública se preserva, a taxa de mortalidade infantil declina e as filas do INPS se descongestionam. Todos temos consciência de que qualquer família pode construir sua casa, mas nenhuma pode construir sua adutora ou sua estação de tratamento de esgoto, que também não se encontra a venda em retalhos ou aos metros, como tijolos, telhas e esquadrias.

42. Solucionar os obstáculos decorrentes da INDIVISIBILIDADE das estações de tratamento de esgoto e a captação, adução e distribuição de água nas cidades, remanescem como UMA DAS MAIORES FALHAS na urbanização das cidades brasileiras. Decorreram 52 anos desde a implantação do PLANASA. TRINTA ANOS DEPOIS DA EXTINÇÃO DO BNH EM 1986, o número de HABITAÇÕES dotadas de água e esgoto continua o mesmo. A falta de água limpa e esgotamento sanitário sobrecarregam os hospitais públicos e ambulatórios.

43. Claro que em outros campos da urbanizaçãoaindaperdemos mais, pois eliminamos a visão de planejamento federal e não a substituímos por outra. O Estado de São Paulo, sempre o pioneiro, evoluiu para o planejamento metropolitano estadual, e regulou os aglomerados urbanos, tornando a intervenção estadual e municipal no urbanismo uma realidade. Dele podemos até discordar, mas existe. De uma maneira geral, houve significativo avanço da consciência nacional de que os municípios devem regular o uso do solo. Embora isto sempre tenha sido feito de forma planejada. A imensidão de áreas mal ocupadas pela urbanização depois da Olimpíada do Rio de Janeiro é um bom exemplo de falta de planejamento adequado.

44. A partir dos anos setenta e oitenta procuramos orientar nosso planejamento urbano e o planejamento metropolitano com FORTE INTERVENÇÃO FEDERAL. Órgãos de atuação NACIONAL foram criados, como o CNDU- Conselho Nacional de Desenvolvimento Urbano que tratava de coordenar as áreas metropolitanas brasileiras; da EBTU- EMPRESA METROPOLITANA DE TRANSPORTES 
URBANOS, todos atuando junto aos Estados e Municípios, com o suporte de entidades do então Ministério do Planejamento, como a SAREM (articulação estadual e municipal) e a SEMOR (modernização administrativa dos estados e municípios) a atuação dessas entidades ainda era uma realidade.

45. Foi com a Constituição de 1988 que se pretendeu, entre outros objetivos, fortalecer os Estados e Municípios que passaram a receber, na partilha tributária, quase tanto como a União Federal. A burocracia federal reagiu ao corte determinado pela Constituição, delegando as atividades e deveres para os Estados e Municípios, alegando que ALEM DOS RECURSOS, deviam também seguir para as entidades estaduais e municipais as funções de governo e responsabilidades.

46. Acontece que o gigantismo da máquina federal continuou inchando e, para sustentar suas pesadas engrenagens, criaram-se novos encargos (tributos disfarçados) como o PIS, o PASEP, a COFINS e outros, beneficiando exclusivamente a União, sonegando aos Estados e Municípios seu quinhão constitucional. Claro que desequilíbrio voltou a ocorrer, sempre em desfavor dos municípios.

47. A eleição do Pte. Fernando Collor de Mello, em 1989, marca um momento ainda mais grave no quadro federal. Entre as novas políticas públicas implantadas, estava o enxugamento da máquina federal, com a extinção de inumeráveis organismos de modernização municipal. Desde então os Estados e Municípios se ressentiram gravemente dos órgãos extintos. Claro que para 100 ou 200 municípios brasileiros mais desenvolvidos e para os Estados mais modernizados, a extinção foi indiferente, mas para outros 5.000 a modernização parou no tempo.

48. Não tenho menor ideia de como os industriais da construção civil, estrangulados pela crise, vão livrar-se dos estoques de apartamentos acumulados. A classe média não tem poder aquisitivo para adquiri-los e os cofres públicos foram raspados na política suicida de financiar infraestrutura e equipamento urbano sem previsão de retorno.

49. Tenho certeza, porém, de que apenas alocar recursos para financiar imóveis estocados só vai servir para aumentar-lhes o preço e dar aos empresários um remédio paliativo. Os problemas estruturais dos sucessivos programas habitacionais brasileiros desenvolvidos durante os últimos cem anos continuam sem solução.

50. Todos esses 140 (cento e quarenta) anos de aprendizado em matéria de políticas públicas de produção que se dita ser capitalista da habitação do Brasil, ensinam, porém, várias lições. Uma delas, clara, cristalina, indiscutível, é que o equacionamento de um programa habitacional realista, repousa na solução da questão fundiária, na definição do modelo de desenvolvimento urbano e na redefinição do direito de propriedade, e não na produção pura da habitação. Sem redefinir o direito de propriedade do Código Civil, não podemos prosseguir.

51. A outra lição talvez, seja ainda mais nítida. Os japoneses patrocinam reformas sem precedentes em sua economia e em suas máquinas burocráticas e, quanto menor for a taxa de governo na economia, melhor. Em outras palavras: quanto menos intervenção estatal houver na atividade privada, melhor será. Esta consciência, aliás, parece estar bem clara no modelo proposto pelo Visconde de Paranaguá ao Imperador D.Pedro II, há mais de cem anos atrás, mas não parece muito aceita no Brasil de nossos dias.

52. Teremos mesmo evoluído? 